\title{
Vivir en la calle: experiencias corporales para pensar los géneros en Bogotá (Colombia)
}

\author{
Carolina Rodríguez Lizarralde' (iD 0000-0002-4700-9374 \\ 'Universidad Nacional de Colombia, Bogotá, Cundinamarca, Colombia. 110911 - \\ docchs_fchbog@unal.edu.co
}

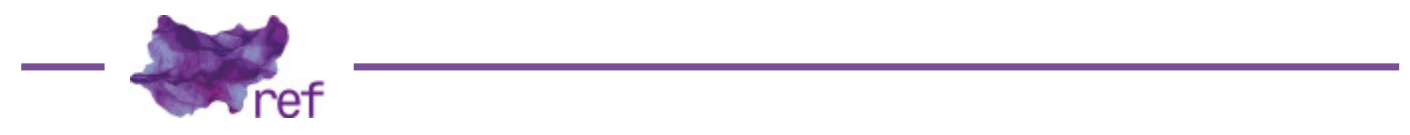

Resumen: Las experiencias callejeras se asumen de manera diferenciada por quienes viven en la calle, espacio donde se ejerce una lectura violenta de lo femenino. Desde un enfoque de género, este artículo pretende visibilizar las construcciones de los cuerpos femeninos y feminizados en Bogotá, situadas en un grupo de niñas y jóvenes entre 14 y 28 años, con quienes se trabajó a partir de una etnografía institucional realizada entre 2012 y 2014, apoyada por talleres con enfoque biográfico, usando la escritura, el sonido y la fotografía, así como las cartografías corporales. Los aportes de esta investigación permiten ubicar nuevas discusiones frente a las experiencias generizadas en la calle, y reflexionar sobre apuestas metodológicas cuando se promueven investigaciones con población en situación de calle como un acto de politización de las cotidianidades de los cuerpos callejeros. Palabras clave: experiencias callejeras; cuerpos femeninos; experiencias corporales; violencia; calle.

Homelessness: Bodily Experiences for Thinking Gender in Bogotá (Colombia)

Abstract: Street experiences are assumed in a different way by those who live on the streets, a space where a violent reading of the feminine is practiced. From a gender perspective, this article aims to make visible the constructions of the feminine and feminized bodies in Bogotá, recognizing the experiences of a group of girls and young women between 14 and 28 years old, with whom we worked based on an institutional ethnography carried out between 2012 and 2014, based on workshops focusing on their biographies through writing, sound and photography, as well as body mapping. The contributions of this research allow us to locate new discussions in the face of the experiences generated on the streets, and to reflect on methodological bets when promoting research with the ones living on the streets to vindicate their rights as political subjects in their daily lives.

Keywords: Street experiences; Feminine bodies, Bodily experiences; Violence; Street.

\begin{abstract}
Morar na rua: experiências corporais para pensar sobre os gêneros em Bogotá (Colômbia)

Resumo:As experiências de rua são assumidas de maneira diferente por aqueles que moram nela, um espaço onde há uma leitura violenta do feminino. A partir de uma perspectiva de gênero, este artigo busca visibilizar as construções de corpos femininos e feminizados em Bogotá, situadas num grupo de meninas e jovens entre 14 e 28 anos, com quem trabalhamos com base numa etnografia institucional realizada entre 2012 e 2014, apoiada por oficinas com uma abordagem biográfica, utilizando escrita, som e fotografia, além das cartografias corporais. As contribuições desta pesquisa permitem localizar novas discussões diante das experiências de gênero na rua e refletir sobre as apostas metodológicas quando se propõem pesquisas com população em situação de rua como um ato de politização do cotidiano dos corpos de rua.
\end{abstract}

Palavras-chave: Experiências de rua; corpos femininos; experiências corporais; violência; rua. 


\section{Introducción}

Los discursos sobre los cuerpos femeninos en la calle generizan las situaciones de riesgo a las que las mujeres habitantes de calle están expuestas, mientras dan relevancia a las experiencias masculinas para vivir en la calle, pasando por alto otros cuerpos, principalmente aquellos que no se ajustan a la heteronormatividad'. De igual manera, el tratamiento institucional ha legitimado lo femenino y las necesidades de sus beneficiarias a partir de imaginarios de ser mujer (madreesposa), restringiendo aspectos de sus experiencias, la gestión de riesgos, los proyectos de vida y las razones para salir a o dejar la calle.

Existe una suerte de invisibilización de lo femenino en calle a partir de las cifras de quienes la habitan. El Censo de Habitantes de la Calle del Departamento Administrativo Nacional de Estadística-DANE (2017) estableció que 9.538 es el total de población habitante de calle censada en Bogotá, distribuida entre 8.477 hombres y 1.061 mujeres, reflejando el binarismo al identificar los cuerpos que viven en la calle. Sin embargo, en los casos en que las personas censadas respondieron a la entrevista directa (sexo declarado), 729 personas se identificaron como mujeres $(10,5 \%), 6$ como intersexuales ${ }^{2}(0,1 \%)$ y 6.211 como hombres $(89,4 \%)$. De esta manera, el resto de población censada por observación se estableció bajo los criterios de personal en campo, y estuvo permeada por la construcción del sexo, el género y la edad de sujetos operadores de las políticas sociales dirigidas a habitantes de calle en el Distrito.

Así mismo, se concibe que la calle no es un lugar para vivir o construir feminidades, pues la pertenencia de las mujeres al espacio privado es la mejor garantía de seguridad e integridad. Sin embargo, cuando se intentan explicar las razones por las cuales las mujeres llegan a la calle, se mencionan, entre otras, las violencias sufridas al interior del hogar, especialmente la violencia sexual por parte de algunos hombres de sus familias o cercanos a ellas. No obstante, ante los nuevos peligros en el espacio público, las mujeres deciden enfrentarlos y asumirlos a través de performance de género que cuestiona la existencia misma de cuerpos femeninos en la calle, lo que hace invisible la presencia de ellas en la calle y les ayuda a evitar ser objeto de violencias en la calle.

Sin duda, la construcción de un cuerpo generizado en calle y la visibilización de sus prácticas se gestan en las prácticas cotidianas, siendo este el escenario de disputa y reflexión. Por tanto, la pregunta que intento responder es: ¿Cómo se construyen los cuerpos femeninos y feminizados en calle? Para ello, retomo el trabajo etnográfico realizado con un grupo de niñas y jóvenes que asistían al Instituto Distrital para la Protección de la Niñez y la Juventud (IDIPRON) y donde, como investigadora, fui moviéndome entre la confianza, el afecto y el rol institucional.

Parto de una postura feminista para leerme y leer los cuerpos femeninos callejeros ${ }^{3}$, reconociendo mis emociones y transformaciones corporales como investigadora, y moviéndome entre un análisis de los discursos institucionales (políticas públicas) y de las voces de quienes hicieron parte de la investigación como chicas en situación de calle (experiencias callejeras), asumiéndome una joven servidora pública en una institución que hasta entonces -en 2011 cuando llegué a trabajar allí-, no había contemplado el papel de las mujeres en la calle, ni se había preguntado por los modelos de atención feminizados que se ofertaba a niñas y jóvenes, ni reconocía la existencia de corporalidades diversas como las personas trans.

En primer lugar, ubicaré la metodología de la investigación y las formas que encontré para trabajar con ellas dentro y fuera de la institucionalidad, con negociaciones como profe, par y responsable de su integridad. En segundo lugar, trazaré lo que se entiende por experiencias corporales, ubicando allí los resultados y la discusión. Finalmente, propongo una reflexión para pensar los cuerpos en calle, principalmente desde los derechos sexuales y reproductivos de quienes la viven.

\section{Metodología}

La investigación se realizó bajo un diseño etnográfico. A partir de cartografías corporales, de mapas andantes realizados en recorridos por la ciudad, del uso de la escritura, del sonido y de la imagen, se entendió que "compartir la historia vital es la manera de narrarse ante el mundo y es también la forma de construir y develar identidades" (Natalia ÁlVAREZ, 2017, p. 52). Así, en el

\footnotetext{
' El primer uso del concepto "heteronormatividad" se dio en el año 1991. Fue Michael Warner quién la definió por primera vez como "el conjunto de las relaciones de poder por medio del cual la sexualidad se normaliza y se reglamenta en nuestra cultura y las relaciones heterosexuales idealizadas se institucionalizan y se equiparan con lo que significa ser humano". La imposición de la heteronormatividad es una consecuencia de la posteridad a la aceptación de la "heterosexualidad obligatoria" (concepto introducido por Adrienne Rich en 1980).

${ }^{2}$ Intersexuales son personas cuyo desarrollo genital presenta características asociadas con pene y vagina de manera simultánea y con diferentes prevalencias.

${ }^{3}$ Los cuerpos femeninos callejeros son cuerpos que han sido inscritos de manera violenta en lo femenino porque se les cuestiona no cumplir con los roles socialmente asignados dentro de la separación binaria hombre/mujer y, precisamente al estar marcados por la calle, son leídos como cuerpos que no deberían habitar ese espacio, es decir, cuerpos abyectos.
} 
espacio biográfico (Leonor ARFUCH, 2010) se ubicaron diversas formas para la construcción de relatos de vida desde los lenguajes propios de las mujeres con quienes trabajé.

Entre los años 2012 y 2014, y en calidad de servidora pública del IDIPRON, obtuve 128 diarios de campo, y trabajé con aproximadamente 70 niñas y mujeres entre 14 y 28 años en las Unidades de Protección Integral (en adelante UPI) de Luna Park, El Oasis, Perdomo y La 32, ubicadas en las zonas del centro y sur de Bogotá. Ellas iban a los diferentes centros de acogida en el marco de los proyectos para la atención a población en riesgo de calle o en situación de calle. Algunas de estas chicas asistían intermitentemente a los programas, por lo que las actividades desarrolladas contemplaron su fluctuación.

El escenario principal fue el IDIPRON, y en ocasiones se desarrollaron acciones como trabajar, comer, dormir, consumir drogas y compartir en familia en espacios callejeros, ajenos a la institucionalidad. Esta etnografía institucional fue considerada el diseño más apropiado, porque la población en situación de calle asistía a las diferentes actividades de manera voluntaria, y me permitía como investigadora acceder a espacios de trabajo previamente establecidos, negociados con funcionarios responsables de las Unidades y con las jóvenes, así como crear unos nuevos en el marco de las actividades institucionales, siendo también profe, ganando la confianza y el afecto. Este fue un aprendizaje que tal vez no se hubiese logrado en calidad de investigadora externa, únicamente asistiendo a realizar entrevistas o grupos focales.

Al compartir la cotidianidad dentro y fuera de la institución, se emplearon lenguajes como el dibujo, la escritura, el sonido y la fotografía ${ }^{4}$. La categoría construida anticipadamente fue experiencias callejeras, y allí se situaron otras como relaciones de género, sexualidad y expresiones de afecto, todas en calle. Sin embargo, sobre la marcha emergió la categoría experiencias corporales, y a la vez permitió emerger la propuesta teórica de cuerpos femeninos callejeros desde una postura feminista para pensar a mujeres heterosexuales, lesbianas y bisexuales, así como personas trans. Entonces, las formas que las niñas y jóvenes encontraron para expresarse a través de los lenguajes propuestos en la investigación se convirtieron en una posibilidad de resistir, de encontrar su auto representación, y de reconocer sus vidas como vidas posibles.

\section{Resultados y discusión}

Pensar las experiencias callejeras y las relaciones de poder en la calle me llevó a considerar las experiencias corporales y a entender que "Ios cuerpos son producto de mediaciones culturales en las que la edad, el género, la clase social, las nociones de salud/enfermedad y las concepciones de público/privado cumplen un rol fundamental" (Eugenia ZICAV; Julieta ASTORINO; Lucas SAPOROS, 2017, p. 1183-1184).

Concibiendo las experiencias corporales como aquellas vivencias que marcan, subjetivizan y objetivizan a los cuerpos como femeninos y que, en la mayoría de los casos, suelen ser violentas, parto por asumir un proceso de feminización en calle. Por un lado, lo femenino en calle es producido a través de discursos y prácticas, es corporeizado mediante marcas corporales, y es generizado en un contexto donde predomina la masculinidad hegemónica ${ }^{5}$, cuyas principales repercusiones son la expresión de violencias sin límites (asesinatos con arma de fuego o arma corto punzante, mutilación, masacres), la inseguridad en sitios como parques, aceras, transporte público, y el sostenimiento de relaciones heterosexuales, en las que el hombre se ubica como el proveedor de alimentación, vivienda, drogas y seguridad (Marina MEDAN, 2014).

De igual manera, se construye una feminidad hegemónica, desde la cual se ubica a las mujeres como objeto de placer y deseo, reproductoras del mundo de la vida en la calle, pero quienes quizás no son dignas de ser parejas estables, pues no cumplen con la condición de encontrarse en el espacio de la casa como cuidadoras, aumentando su riesgo de victimización y rechazo por no cumplir con la norma. En esta reproducción de roles generizados, los discursos y las prócticas institucionales también tienen responsabilidad, tal como lo afirma el documento de política pública (2015) del fenómeno de habitabilidad en calle:

La calle no es naturalmente atractiva para las mujeres porque es el símbolo de los peligros: violaciones, agresiones, robos y demás actos contra la integridad física y humana que se acentúan en la población femenina por su "vulnerabilidad natural", su posicionamiento como objeto de deseo y la construcción del hombre desde la fuerza, la superioridad y la autoridad. Pensar en vivir en la calle bajo este escenario resulta demasiado riesgoso, difícil de pensarse y muy costoso desde cualquier punto de vista, por eso muy pocas mujeres se atreven hacerlo. (ALCALDÍA MAYOR DE BOGOTÁ, 2015)

\footnotetext{
${ }_{4}^{4}$ Para efectos de este artículo, se ubicarán las narraciones de los diarios de campo e imágenes tomadas por las jóvenes durante el proceso, privilegiando relatos generados en momentos etnográficos o la realización de actividades institucionales.

${ }^{5}$ El concepto de masculinidad hegemónica se utiliza a partir de 1985, y surge cuando un modelo de comportamiento masculino logra imponerse, originando una situación de desigualdad, como el reproducir modelos de atractivo de hombres violentos.
} 
En este sentido, y desde una mirada institucional, la diada ser mujer y vivir en la calle facilita naturalizar las violencias que sufren los cuerpos femeninos y omitir protocolos, que en otros casos, y para otras mujeres, se activarían ante situaciones como la violencia sexual y el embarazo. Ser mujer en la institución implicaba iniciar un proceso cuyo final era volver a la casa, tener hijos que las obligara a cambiar el estilo de vida callejero y encontrar un hombre que no viviera en las mismas condiciones de calle para salir adelante, cumpliendo con expectativas sociales de la feminidad.

Es así como los cuerpos de las mujeres que viven la calle son subjetivizados/objetivizados por la política social, y se proyectan como imágenes de lo invivible en dicho espacio. Dentro las prácticas discursivas institucionales y la oferta de servicios sociales, estos se han generizado bajo regímenes del deber ser de lo femenino, como cuerpo biológico anterior -no como proceso-, y donde la diferencia sexual marca las corporalidades e impone una lectura de las subjetividades. Esto se ve reflejado en los programas y servicios de atención dirigidos a mujeres en el Distrito de Bogotá, mostrando que

La política social como dispositivo para la producción de sujetos/objeto de intervención se ha encargado de construir discursos y prácticas que se traducen en servicios sociales. Estas prácticas discursivas materializan cuerpos y por medio de la reiteración ordenan realidades, es así como los servicios se vuelven homogeneizantes y normalizan la diferencia. Las políticas están impregnadas de prejuicios sexistas y estereotipos de género; quienes hacemos parte del aparato estatal logramos naturalizar y reproducir estos dispositivos en el quehacer cotidiano, e incluso, vulnerando los derechos de quienes buscamos "proteger". El hecho de que Idipron haya permitido la posibilidad de repensar sus prácticas cotidianas desde una perspectiva de género, ha sido una oportunidad para releer los cuerpos que se producen desde el discurso institucional y abrir opciones de mejoramiento de políticas, planes y proyectos. (Carolina RODRÍGUEZ, 2015, p. 116)

En la calle se construye lo femenino como inscripción corporal dotada de significados y allí se les corrige para que cumplan con la norma y sean valorados como lo que deberían ser: cuerpos que responden al requerimiento de femininidad, que implica no ser callejeros. Incluso yo, como joven investigadora feminista, y aunque mi cuerpo no fuese marcado como callejero, tuve que transformar modos de andar, vestir y llevar mi pelo para deambular por las calles en diferentes horarios, principalmente en la noche. Recuerdo pasar desapercibida en grupos de compañeros del IDIPRON, quienes se encargaban de invitar a jóvenes a las Unidades de atención, así como el adjetivo profex me asumía parte de aquellos que podían estar haciendo el trabajo en la calle. Darme un lugar en los equipos territoriales del Instituto fue difícil con un cuerpo femenino, que a la vez era feminizado y cuestionado cuando decidía caminar sola en la noche o interactuar con personas callejeras en los barrios focalizados. Con mi cuerpo, experimenté cómo se construye desde la institucionalidad un cuerpo feminizado e incapaz de aguantar la realidad de la calle, así como la necesidad de andar siempre acompañada y obligándome a cambiar u ocultar cualquier rasgo que me pusiera en desventaja ante mis compañeros.

Para dar cuenta de las experiencias corporales de mujeres en situación de calle, se organizaron sus narrativas en las subcategorías violencia sexual, prostitución, menstruación, planificación y gestación. Su elección tuvo en cuenta, por un lado, la necesidad de mostrar la vulneración de los derechos sexuales y reproductivos como mujeres callejeras -menstruación, planificación y gestación-; por otro lado, visibilizar el carácter diferencial de la vida en calle de cuerpos femeninos, que en los casos de violencia sexual y prostitución dan muestra del proceso de feminización. Los hallazgos hacen énfasis en los diarios de campo desde la voz de la autora del texto, las protagonistas de la investigación y, en algunos casos, se muestran imágenes tomadas por ellas durante el proceso.

\section{Relatos sobre violencia sexual, resistencias y autocuidado en calle}

Iniciar por las experiencias de violencia sexual fue una decisión por visibilizar las conversaciones sostenidas con las mujeres y reflejadas en mis diarios de campo. Los distintos espacios de interlocución siempre llevaban a narraciones de cómo sus cuerpos habían sido objeto de violaciones (acceso carnal violento), tocamientos, y poco se habló del acoso sexual callejero. Desde mi postura feminista como joven mujer e investigadora, la violencia sexual es una de las formas en que los cuerpos de las mujeres son feminizados de manera violenta, recordándoles que son objeto de deseo y placer desde lógicas masculinas en la calle. A la vez, explica cómo los cuerpos femeninos son asumidos desde el menosprecio, la subvaloración y la discriminación. Rita Laura Segato argumenta que:

1) la expresión «violencia sexual» confunde, pues aunque la agresión se ejecute por medios sexuales, la finalidad de la misma no es del orden de lo sexual sino del orden del poder; 2) no se trata de agresiones originadas en la pulsión libidinal traducida en deseo de satisfacción sexual, sino que la libido se orienta aquí al poder y a un mandato de pares o cofrades masculinos que exige una prueba de pertenencia al grupo; 3) lo que refrenda la pertenencia al grupo es un 
tributo que, mediante exacción, fluye de la posición femenina a la masculina, construyéndola como resultado de ese proceso; 4) la estructura funcional jerárquicamente dispuesta que el mandato de masculinidad origina es análoga al orden mafioso; 5) mediante este tipo de violencia el poder se expresa, se exhibe y se consolida de forma truculenta ante la mirada pública, por lo tanto representando un tipo de violencia expresiva y no instrumental. (SEGATO, 2016, p. 18)

De esta manera, hacer parte del orden de la calle implica el sometimiento al mandato de masculinidad en este territorio, donde se legitiman las agresiones. Sin embargo, las historias de abuso sexual al interior de los hogares de las niñas y las jóvenes también fueron comunes en el trabajo de campo. En primer lugar, se argumentó la decisión de salir a la calle como posibilidad de huir de las manifestaciones violentas por parte de familiares o personas cercanas a sus familias.

Yo soy del Quindío, tengo 16 años y decidí venirme para Bogotá porque mi padrastro abusaba de mí. Llegué a vivir a Soacha (Cundinamarca) y alguien me ofreció trabajo en Bogotá en el Bronx. Por eso estoy acá. (Diario de campo, 2013)

En segundo lugar, la capacidad de salir del hogar, entendido éste como espacio seguro, mostró que ellas toman la decisión de irse porque precisamente no les significa cuidado y protección. Sin embargo, en la calle también experimentan la violencia sexual por parte de individuos que ganan su confianza, personas que abusan del poder y personas desconocidas que operan desde el asalto sexual. Así, por ejemplo, en mujeres heterosexuales se encontró que sus parejas hombres lograron ganarse su afecto y confianza para explotarlas sexualmente, e incluso para intercambiarlas por dosis de droga, o entregarlas a un grupo de amigos con el fin de sostener relaciones sexuales múltiples. Claudiab narró que

Llegó a la L a trabajar como "taquillera", es decir, como la persona que entrega las dosis de droga y recibe el dinero. Cuenta que llevaba dos días sin dormir para lograr turnos mejor remunerados... se quedó dormida un rato y su novio le robó 70 mil pesos de la taquilla. Cuando el "patrón" llegó le reclamó el dinero y éste estaba incompleto. La primera reacción fue golpearla y llevarla para una pieza donde la obligarían a confesar...le dio tres puñaladas.

Buscando testigos, el novio de la chica afirmó que ella se había robado la plata y el "patrón" encendió una cortadora o sierra para cortarle el brazo, obligándola a decir la verdad. Ella le decía que se había quedado dormida y que no sabía quién había cogido el dinero, esto no bastó para que le perdonaran la deuda. Dentro del hospital recibe una visita de su agresor, quien se hace pasar por su tío y se la lleva nuevamente a trabajar gratis para reponer el dinero perdido.

Algunas personas que les brindaban apoyo en términos económicos o en especie (comida, vivienda, útiles de aseo), e incluso empleadores como jíbaros (dealers), coordinadores de bodegas de reciclaje, entre otros, abusaban de su posición de poder para acceder carnalmente a sus cuerpos, e incluso para someterlas bajo modalidades de servidumbre sexual ${ }^{7}$ cuando no se cumplía con cuotas o rendimientos económicos frente a los negocios ilegales, principalmente en los casos de compra y venta de estupefacientes.

En tercer lugar, pese a considerarse la calle como el espacio menos seguro para lo femenino, especialmente para quienes la habitan, los relatos de asalto sexual por parte de desconocidos fueron muy escasos, mostrando que su ocurrencia casi siempre tuvo relación con engaños por parte de una o dos personas que eran reconocidas por las niñas y jóvenes. De igual manera, la pérdida de recuerdos dado el uso de alucinógenos, en algunos casos las hacía percibir que los violadores eran desconocidos, y luego se enteraban que estas personas eran cercanas a sus trayectorias cotidianas.

Finalmente, la violencia sexual es un asunto normalizado en las mujeres que viven la calle. Por un lado, ellas desconocen las rutas de atención y de denuncia, y por el otro, dentro de la institución no se promueven protocolos que permitan acceder a los servicios atención. Por tanto, para ellas está la necesidad de protegerse y pararse duro en la calle, con el fin de evitar la ocurrencia de estas violencias. En caso de suceder, hay formas para cobrar venganza, alejarse de ciertos lugares, o simplemente aprender a moverse para que no suceda nuevamente, que podemos considerar medidas de autocuidado y cuidado mutuo por la advertencia de otras mujeres frente a los posibles riesgos que se corren con ciertos personajes o grupos en la calle.

Por estas razones, la violencia sexual marca sus experiencias corporales, tanto al interior del hogar como en el espacio público, y se convierte en un factor importante para pensar cómo la calle plantea riesgos de acuerdo con lo que se construye como lo femenino hegemónico, primando la heterosexualidad obligatoria y controlando aquellos cuerpos que no siguen dichas reglas (heterosexuales, bisexuales y lesbianas). Este tipo de violencia es la más prevalente y la que

\footnotetext{
${ }^{6}$ Los nombres de las jóvenes han sido cambiados para mantener la confidencialidad de las narraciones.

${ }^{7}$ Asumida aquí como el pago a través de servicios sexuales al interior de un establecimiento o un alojamiento, cuyo sometimiento terminaba luego de saldar la deuda.
} 
recuerda por qué están en un lugar que no es para las mujeres, reforzando la idea del peligro que enfrentan, y buscando protegerse, principalmente al no caminar o permanecer solas, o tratando de pasar desapercibidas (invisibles) que, simbólicamente, se refleja en la fotografía tomada a una joven que cubre su rostro.

\section{Figura 1 - Tápese pa' la foto}

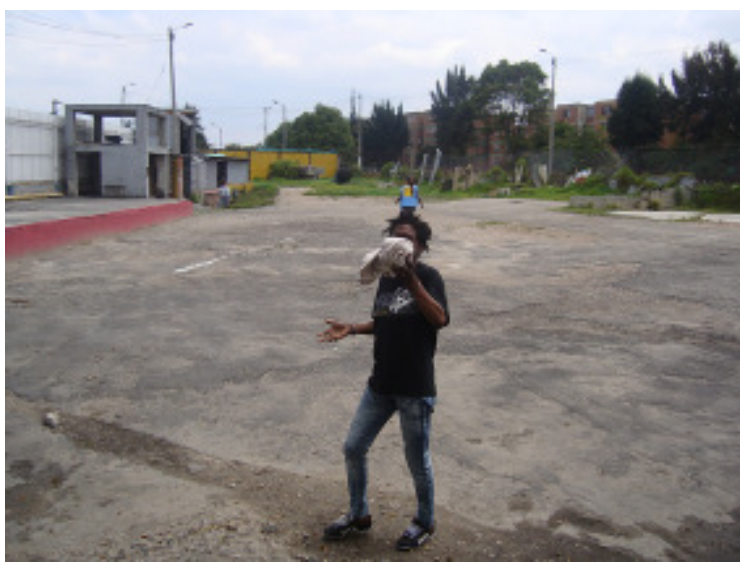

Fuente: Jóvenes de Luna Park, 2013.

\#PraTodoMundoVer La fotografía, tomada por jóvenes de la Unidad de Protección Integral Luna Park, es de una mujer en primer plano. Es negra, flaca, tiene melena con rulos, lleva camiseta negra con detalles blancos, jeans azules, pulseras en los dos brazos y zapatillas deportivas. Recién salida del baño, ella aparece caminando en el patio, mira la cámara fotográfica, abre un poco el brazo y la mano derecha, y esconde el rostro con la toalla enrollada que lleva en la mano izquierda. Al fondo se observa una funcionaria del IDIPRON, quien se dirige a la portería, así como el patio lleno de pasto y pisos deteriorados, mostrando el descuido del lugar para la atención de las mujeres en situación de calle en Bogotá.

Algunas formas que encontraron las mujeres para protegerse de la violencia sexual fue restringirse de caminar 0 dormir en las noches, resguardarse en los centros de alojamiento 0 conseguir una pareja, en caso de acampar en andenes, riveras de ríos, debajo de los puentes o en espacios abiertos con improvisados cambuches ${ }^{8}$. Otras intentaban no ser leídas como mujeres, evitando ser blanco de violencia sexual, tal como lo refleja el relato de Lorena: "Ias mujeres en la calle perdemos la feminidad porque nos toca buscar formas para que los hombres no abusen de nosotras; por eso se ve tanto chachito (asociación con lo masculino)", relato que cuestiona la existencia misma de la categoría mujer en la calle y la dicotomía en la construcción de los cuerpos callejeros.

Así mismo, es pertinente un análisis de la violación de un hombre trans, cuyo resultado fue un embarazo no deseado y un parto que le recordaba la determinación del sexo socialmente construido.

"Profe imagínese que hace un año tuve una hijita", me contó Andrés recién llegué al Oasis. Esto me sorprendió porque él se asumía como hombre... entonces le pregunté: ¿Decidiste tenerla? $Y$ me respondió: Me violaron en la $L$ porque tenía unas cuentas pendientes, me tocó esconderme durante el embarazo, tenerla y dejársela a mi mamá. (Diario de campo, marzo 2014)

La anterior experiencia muestra que las estrategias de protección ante la violencia sexual son poco efectivas por parte de los cuerpos callejeros, construidos y leídos como femeninos, donde finalmente priman las valoraciones en cuanto a los genitales y aparatos reproductores. Lo anterior también marca una relación con los embarazos no deseados, resultado de la violencia sexual. Finalmente, a esta falta de efectividad de mecanismos de prevención se suma la normalización de los casos dentro del IDIPRON y la falta de socialización de rutas de atención por parte de entidades como la Secretaría de Salud y Medicina Legal frente al abordaje con habitantes de calle en Bogotá, incluso cuando algunas eran menores de 18 años.

\section{Ser o no ser madre durante la permanencla en calle}

En mi trabajo de campo tuve contacto con seis mujeres embarazadas, donde solo la mitad (3) decidió internarse en IDIPRON y otras optaron por llevar su proceso de gestación en situación de calle. Ubicar este tema como subcategoría cobró relevancia porque ninguno de los embarazos que fueron narrados durante la investigación se manifestó deseado, debido a que había sido producto de violencia sexual (1), se había roto con la relación de pareja que había concebido (1), o porque la adicción a las drogas hacía más importante la necesidad de estar en la calle y poder consumir, incluso durante el embarazo sin perder su libertad (2).

Frente a las estrategias de planificación, una de las prácticas institucionales en las Unidades de atención a mujeres en situación de calle fue la promoción del implante subdérmico como método de planificación, buscando que su efecto entre tres y cinco años lograse evitar que más niñas y jóvenes quedaran embarazadas. Sin embargo, es preciso advertir dos situaciones: la primera, una normalización de la violencia sexual antes referida, que previene embarazos por

\footnotetext{
${ }^{8}$ Los cambuches son tiendas de acampar ubicadas en el espacio público, las cuales se elaboran con madera u otros
} materiales reciclados. 
esta vía, y la segunda, evitar un embarazo cuando se sostenían relaciones con parejas hombres en situación de calle, quienes estaban en igual o peores condiciones. A los procesos de planificación se involucraron mujeres lesbianas, quienes manifestaron no requerir de este tipo de métodos, dada su orientación sexual.

La promoción de la planificación estaba guiada bajo parámetros donde la mujer es la responsable de no quedar embarazada, y en ningún momento se manifestó la responsabilidad compartida por los hombres, o incluso no se hace un duro cuestionamiento a la violencia sexual por parte de las personas vinculadas a los servicios de atención.

Por ejemplo, una funcionaria afirmaba que: "esa chica no aprende. Varias veces ha llegado acá sin poder casi ni caminar porque la violan entre varios tipos... la mamá una vez vino a visitarla y se agarraron a gritos! Ese día no la dejamos entrar a la unidad porque es muy grosera con las demás" (Diario de campo, marzo 2013), mostrando cómo las jóvenes son juzgadas y castigadas por su permanencia en calle y su relación conflictiva con la familia, sin cuestionar la violencia sexual de la que son víctimas.

En términos de gestación, en algunas narraciones se encontró que las mujeres tuvieron embarazos de alto riesgo, así como abortos en los primeros tres meses, dadas las condiciones en las que vivían. Se encontró dos chicas que nunca habían recibido un control médico prenatal, porque no sabían que se encontraban embarazadas o porque no acudían a los centros de salud, pues dudaban que las atendieran por su situación de calle, y no contaban con afiliación a Empresas Promotoras de Salud (EPS) o no acudían a los espacios de institucionalización que les permitiera iniciar proceso de controles médicos. En los tres casos de mujeres embarazadas, ellas tenían que ser llevadas y acompañadas por personal de enfermería del IDIPRON, logrando ecografías y cálculos en crecimiento del feto, así como posibles tiempos para el parto.

Una de ellas, Vanessa, estaba embarazada. Cuando la conocimos tenía 3 meses de embarazo y no se había practicado ningún examen, tampoco contaba con cédula de ciudadanía y era consumidora de marihuana. La facilitadora de calle la motivó y acompañó a gestionar la cédula y una cita en su EPS. Luego de un mes de contacto con ella, se podría afirmar que su situación había cambiado en términos formales (de documentación), pues en realidad tenía que ir los lunes, miércoles y viernes a reciclar al norte de la ciudad y lo hizo hasta el último mes de embarazo, pese a una hernia en su recto por el peso de empujar una carretilla. (Diario de campo, noviembre 2012)

Cabe señalar que otra de las mujeres embarazadas no permaneció en su proceso de institucionalización y abandonó el alojamiento o internado. En los dos casos que conocí, donde los embarazos culminaron en parto, las mujeres dieron a luz de manera prematura, es decir, entre los seis y ocho meses. En estos casos, las mujeres tuvieron sus bebés y continuaron su vida en la calle, quedando a cargo de los recién nacidos algún familiar o alguna institución de adopción adscrita al Instituto Colombiano de Bienestar Familiar (ICBF) ${ }^{9}$. Sin embargo, los discursos institucionales se soportaban en la invitación a que las mujeres se hicieran cargo de su maternidad, incluso proponiendo ésta como una posible salida de calle y posibilidad de asumirse como madre para adquirir responsabilidad sobre la vida de otro ser humano. Esto permea también en sus formas de autorreferenciarse,

Yo tengo cinco hijos y ellos viven con mi mamá y mis hermanos, en algún momento yo me quiero salir de la calle para vivir con ellos, pues ya bastante ha tenido que aguantar mi mamá conmigo... pero la verdad es que no he tenido la fuerza de voluntad para hacerlo, y luego digo que si salgo lo hago por mí y por nadie más. (Diario de campo, julio 2013)

Esta narración refleja que si bien, por un lado, el discurso del cambio y la salida de calle ha permeado las experiencias de las mujeres, por otro lado, estos no logran la efectividad que institucionalmente se espera, sobre todo en el rol de la maternidad, reforzando el ideal de mujermadre y su naturaleza o instinto maternal frente a una situación compleja como la calle. Entonces, en la lectura violenta de lo femenino, también aparece la maternidad impuesta (al menos como discurso) que lleva a las mujeres a cuestionar su lugar en el mundo, o a "darle sentido a su existencia" mediante un rol que no eligieron ni planearon, pero que se les ofrece como su "salvación" frente la vida callejera que llevan y liberación de la culpa. Sin embargo, las experiencias corporales dan cuenta de un cuestionamiento a la maternidad impuesta por el hecho de "ser mujeres", lo que implica nuevas investigaciones que asuman el tema.

La planificación, el embarazo y la maternidad terminan siendo un asunto relevante para analizar los cuerpos construidos como femeninos, y es, quizás, la apuesta más potente al momento

\footnotetext{
9 El Instituto Colombiano de Bienestar Familiar - ICBF, es la entidad del estado colombiano que trabaja por la prevención y protección integral de la primera infancia, la niñez, la adolescencia y el bienestar de las familias en Colombia, brindando atención especialmente a aquellos en condiciones de amenaza, inobservancia o vulneración de sus derechos, llegando a más de 8 millones de colombianos con sus programas, estrategias y servicios de atención con 33 sedes regionales y 211 centros zonales en todo el país. Ver: https://www.icbf.gov.co/instituto
} 
de plantear posibles salidas de la calle, reforzando precisamente el ideal de mujer-madre. A la vez, se produce una tensión entre la maternidad vista como salida, cuando ésta no se ha decidido, y la planificación como estrategia para evitar que más mujeres en calle queden en embarazo, bajo el cuestionamiento de ellas como madres descorazonadas, enfatizando finalmente sobre la motivación por recuperar a sus hijos en un proceso de internado e integración a sus familias.

La pregunta que surge entonces es: ¿Están las mujeres callejeras decidiendo sobre sus cuerpos frente a la opción de tener hijos? Por ahora, la respuesta es no. En primer lugar, debido a los índices de violencia sexual presentes en la calle, que están aún sin calcular; en segundo lugar, por la dependencia a drogas alucinógenas que las inhibe frente al control de su cuerpo; y, en tercer lugar, por la falta de acceso a programas de salud sexual y reproductiva dirigidos a población en situación de calle en Bogotá.

\section{Menstruación en la calle}

Los ciclos menstruales de las mujeres en situación de calle son un tema tabú cuando se piensa en cómo se enfrenta dicha condición en el espacio público. En las narraciones de las niñas y jóvenes se encontró una relación poco grata con su sangrado, porque la mayoría de ciclos estaban atravesados por imposibilidades de acceder a insumos de aseo (toallas higiénicas o tampones) y de cambios de vestuario, en caso de manchado, "el problema es que la gente menstrua y ahí viene la cuestión de la higiene, y, si no tiene albergue, usted se queda semanas sin tomar baño, con ropa sucia, porque no se puede lavar" (María Cristina RIBEIRO et al., 2016, p. 752).

El uso de sustancias psicoactivas también genera realidades alternas, hipersensibilidad o pánico cuando se tiene el periodo menstrual. Una de las jóvenes narró que cuando estaba bajo los efectos del bazuco, se aumentaba su miedo a estar manchada, e incluso sentía que toda la gente a su alrededor se le burlaba por estar sangrando o ver su ropa manchada de sangre. Otras chicas de calle contaban cómo durante su menstruación acudían a la mendicidad, o a la solicitud de dinero o paquetes de toallas higiénicas a la salida de establecimientos comerciales. Empero, la forma más fácil de resolverlo era asistir a los centros de atención del distrito y garantizar la entrega por parte de las enfermeras o facilitadoras de kit de aseo al interior de la institución. Recuerdo la llegada de una chica con su pantalón lleno de sangre menstrual. Para mí fue impactante ver su ropa, su mirada perdida bajos los efectos de alguna droga. Sobre todo, pensé en el proceso de lavado de su ropa en la única lavandería del lugar, y en que le tendrían que dar ropa interior, toallas higiénicas y prestarle una sudadera mientras se secaba la muda de ropa que llevaba (Diario de campo, 2013).

La menstruación es una forma de recordarles los procesos biológicos de ser mujeres, aunque en las conversaciones se admitía que sus ciclos no son regulares, y que en algunos casos el sangrado era muy escaso por la falta de alimentación y como reacción al consumo de sustancias psicoactivas. Otras reconocían que no tenían control sobre sus ciclos, y que esto les impedía atender a métodos de planificación o prevención del embarazo.

De la menstruación parece no hablarse, o no querer hablarse... sin embargo, las chicas en la Unidad Luna Park tenían que ganarse su paquete de toallas higiénicas, mostrando con educadoras que estaban dispuestas a mantener el orden en el internado, haciendo aseo o ayudando con otras tareas solicitadas. Así, dentro de la misma institución se asumía que nada es gratis, y que, para obtenerlo, las mujeres tenían que someterse a diferentes reglas, tanto en la calle como en el IDIPRON. Aquí, como servidora, tuve la oportunidad de intervenir y negociar con las jóvenes callejeras, apoyándoles con dinero para la compra de insumos de aseo o solicitando a otras funcionarias la entrega a las chicas. Un último asunto frente a la menstruación tiene que ver con los tiempos de sangrado compartidos por varias mujeres durante los mismos días. Como suele pasar en cárceles, y en general en lugares de habitación de dos o más mujeres, los ciclos menstruales estaban sincronizados cuando convivían juntas. La anterior situación generaba aumento de demanda de utensilios de aseo para la correspondiente Unidad de Protección Integral.

Visibilizar la menstruación en situación de calle, así como las dinámicas institucionales que se transforman dentro de las UPI a raíz del sangrado, es un asunto que reivindica la necesidad de pensar de manera diferenciada en los servicios que se ofrecen a las mujeres menstruantes, cuando se llega con diferentes propuestas a trabajar con ellas en la calle. Durante los ciclos, no basta con ofrecer opciones de baño o ropa limpia, teniendo en cuenta que algunas de ellas piden con vergüenza toallas higiénicas a funcionarios. Entonces, el abordaje debe superar un tema de aseo personal, para convertirse en una propuesta por hacer conciencia sobre los cambios hormonales que viven en calle, y, a la vez, ver reflejado esto en los centros de atención, con el fin de lograr que las chicas encuentren dicho un lugar cuidadoso, amoroso y protector de sus ciclos.

\section{"Vender el cuerpo", prostitución en calle}

Decir que algunas de las mujeres callejeras se sostienen económicamente del ejercicio de prostitución puede parecer obvio; sin embargo, quienes lo reconocen, cuestionan la asociación 
directa de ellas con la prostitución como parte de la exposición pública de sus cuerpos. En primer lugar, como dinámicas en la calle se pueden evidenciar la explotación sexual comercial de niñas, niños y adolescentes (ESCNNA), el proxenetismo por parte de parejas heterosexuales y homosexuales, así como el trabajo sexual en mujeres heterosexuales y mujeres transgénero.

La explotación sexual por parte de familiares, en algunos casos cuando se encontraban al interior de sus hogares, y también en la calle, dan cuenta de diferentes tipos de ESCNNA en el espacio público y algunos establecimientos de acceso restringido por considerarse ilegales, así como fueron intercambiadas por pagos de mercado, alquiler de residencias o cualquier otro beneficio para sus explotadores.

Cinco relaciones heterosexuales y homosexuales que conocí estaban basadas en la explotación sexual por parte de la misma pareja. Este es el caso de una pareja de lesbianas, donde una de ellas vigilaba a su compañera para el ejercicio de prostitución en la Plaza de La Mariposa en el centro de la ciudad, y luego administraba el dinero recibido. En casos de parejas heterosexuales, se encontró que los hombres veían a las mujeres como objetos de su propiedad, y por tanto las ofrecían al interior de las ollas (sitios de expendio y consumo de drogas) para obtener dosis personales, o para saldar deudas pendientes.

En segundo lugar, las jóvenes heterosexuales, bisexuales y lesbianas mostraron vergüenza de admitir abiertamente que hacían ratos $^{10}$, pero en su motivación de estar vinculadas a los programas de atención, encontré que una de las razones fue mejorar su alimentación y superar el excesivo adelgazamiento, lo cual tiene efectos directos en la cantidad de servicios sexuales que obtienen, dado su deterioro físico.

El uso de tatuajes en zonas del cuerpo como los senos, la espalda baja o cerca a los hombros está asociado al erotismo y el deseo que sus cuerpos pueden producir, al igual que los piercings en el ombligo, la lengua y las orejas. Dichas intervenciones corporales también cobran sentido cuando de conseguir clientes se trata, deseando tomar sobre ellas fotografías como la que presento a continuación:

Figura 2 - Vuela mariposa

Fuente: Jóvenes de Luna Park, 2013

\#PraTodoMundoVer La imagen fue tomada durante una cartografía corporal y muestra la espalda de una joven, con un tatuaje cercano a su hombro derecho. El tatuaje está hecho con tinta negra que dibuja una mariposa con proyección de alas con curvas triangulares y dos antenas que salen de la cabeza.

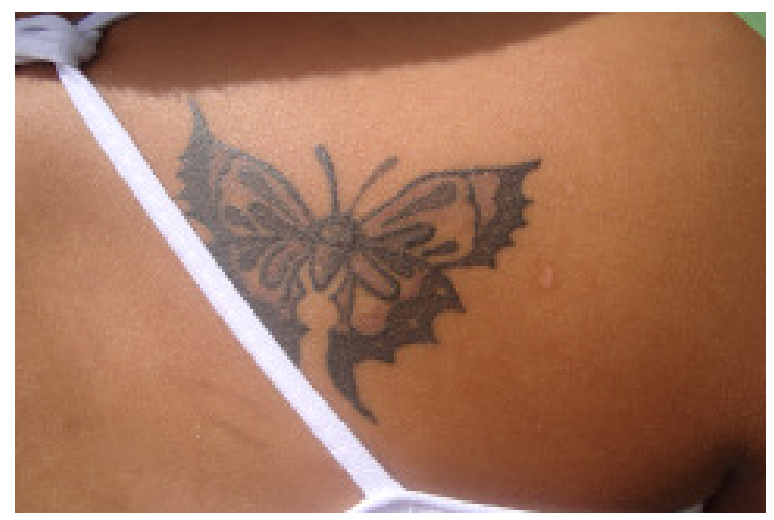

Las mujeres transgénero sí se nombran abiertamente como trabajadoras sexuales o putas, y al interior de las Unidades de Protección Integral del IDIPRON manifestaron prestar sus servicios sexuales: "aquí en El Oasis yo tengo mi clientela, por eso me toca venir de vez en cuando, Usted sabe que en el patio es más fácil que mis clientes me contacten" (Diario de campo, 2014), teniendo en cuenta la dificultad para llamar por teléfono o para ubicar a las mujeres trans callejeras, así como la necesidad de asegurar cierto dinero a la vez que se asiste a un servicio brindado por el Estado.

En los recorridos en calle, se encontró que las trayectorias de las mujeres también son distintas, al menos en el centro de la ciudad. Por ejemplo, hay lugares de uso exclusivo para las mujeres trans en el barrio Santa Fe, así como clientes que se disputan tanto en el espacio público como en los prostíbulos. Sin embargo, trabajar en la calle requiere de unos mínimos de presentación personal y de indumentaria, por lo que ellas evitan que quienes acceden por dinero a sus servicios sexuales, las identifiquen como habitantes de calle.

En tercer lugar, "a nivel simbólico el cuerpo de la mujer que ejerce la prostitución excluye la maternidad en cuanto concreta la división entre erotismo y procreación" (Macarena TRUJILLO, 2017 , p. 171). El discurso que operaba era el abandono de los hijos para continuar el ejercicio de la prostitución, pero más allá de ello extender el periodo de habitabilidad en calle. Por tanto, había un reconocimiento mucho más potente de ser habitante de calle que de ser prostituta, lo que también generaba una vulnerabilidad en términos de falta de cuidado ante infecciones o enfermedades de transmisión sexual, planificación e invisibilización de otras dinámicas como la explotación sexual y la trata de personas.

${ }^{10}$ Es la denominación que le dan las mujeres a los servicios de trabajo sexual. 


\section{Reflexión final}

Con una mirada crítica y reflexiva de mis postulados sobre el género en la calle, encuentro que el trabajo por hacer es de largo aliento y que como apuesta de interseccionalidad, su movimiento está en progreso. Sin duda, el impulso académico dado por algunas investigadoras jóvenes, y quienes trabajamos en Bogotá, configura un trabajo periférico o de frontera, encarnando mi posición desde el lugar que construyo conocimiento (Tania PÉREZ-BUSTOS, 2017). Hago parte del Grupo de Estudios Callejeros - Maquia, cuyo objetivo es visibilizar las experiencias de lo femenino en la calle que, partiendo de la intuición, el trabajo con mujeres callejeras y la reflexión teórica, contribuyan a pensar el género en el espacio calle.

Quiero enfatizar en el vacío frente a los derechos sexuales y reproductivos de las mujeres callejeras. Los resultados presentados dan cuenta de los procesos de construcción de los cuerpos como femeninos en relación con los ciclos biológicos de la menstruación, la planificación y el embarazo, así como con la feminización violenta por medio de las violaciones sexuales y la explotación sexual. Las experiencias corporales de las jóvenes con quienes he trabajado también plantean tensiones entre su propia construcción de lo femenino, las acciones en calle para desmarcarse o marcarse como mujeres o para romper con la dicotomía de género y los discursos institucionales que leen los cuerpos femeninos callejeros desde una feminidad hegemónica, donde se les cuestiona estar en el espacio público, y viendo la calle como un espacio donde impera la masculinidad hegemónica y la heterosexualidad obligatoria, como reflejo de los espacios domésticos cargados de violencia (Márcia Rebeca ROCHA DE SOUZA; Jeane FREITAS DE OLIVEIRA; Mariana Cavalcante GUEDES CHAGASA; Evanilda SOUZA DE SANTANA CARVALHO, 2016; Anderson DA SILVA ROSA; Anna Cristina PASARELLA, 2015).

Por medio de las narraciones se puede plantear que las cuatro temáticas abordadas fomentan una lectura violenta de lo femenino, y una refeminización desde el ejercicio de múltiples violencias. "Así, la refeminización de las mujeres parece una excusa que viene después de la pérdida de las prerrogativas masculinas, una manera de tranquilizarse, tranquilizándoles" (Virgine DESPENTES, 2018, p. 25). La presencia, en aumento, de mujeres en la calle ha llevado a los hombres a emplear mecanismos como la violencia sexual para mantener los privilegios de lo masculino en este espacio y posicionarse como los protectores de lo femenino lo público, es decir que la prostitución está bajo el control de lo masculino (Carole PATEMAN, 1995).

De igual manera, se considera que las necesidades de higiene, alimentación y reposo no son suplidas en la calle para las personas que la habitan; es posible destacar que el reposo sobre todo cobra importancia en el miedo a dormir en las noches, a estar en la intemperie, o a buscar una pareja para asegurarse el derecho al descanso; sin embargo, la misma institución como ente de protección también busca controlar, disciplinar y administrar los cuerpos de las mujeres, a través de discursos y prácticas concretas como el aseo, la maternidad, la invisibilización de las violencias sexuales y la sanción por las identidades de género u orientaciones sexuales que construyen las chicas en calle.

Las experiencias corporales presentadas se mueven entre lo biológico y lo culturalmente construido, y sin duda marcan los cuerpos callejeros desde la generización violenta de lo femenino, donde será necesario generar nuevas investigaciones dirigidas a observar desde la interseccionalidad (Mara VIVEROS, 2016), pues las formas de leer estos cuerpos en la calle están dadas por el proceso de construcción de unos discursos sobre lo femenino, que no determina una sujeción al género, sino más bien una lectura en términos interseccionales entre señales fuertes de sujeción o dominación, así como cuestionan la dicotomía de los géneros (María LUGONES, 2005, citada en María José MAGLIANO, 2015). Es posible pensar en los cruces entre género, orientación sexual, edad, raza, etnia, entre otros que generan la necesidad de crear coaliciones o reivindicaciones desde un estilo de vida y una clase social que se nombra como habitantes de la calle.

Frente al interés por reflexionar sobre los derechos sexuales y reproductivos en calle, vale la pena resaltar que en las mujeres en situación de calle se reproduce con mayor fuerza la negación de la autonomía sobre sus cuerpos, principalmente por la connotación que tienen ser adictas a las drogas, no tener parejas estables, no se les piensa como creadoras de una familia, y aunque varias de ellas son madres, se parte por invisibilizar sus decisiones sobre cuántos hijos tener.

Según la Política Nacional de Sexualidad, Derechos Sexuales y Derechos Reproductivos en Colombia, los principios de igualdad, equidad, diversidad y no discriminación, libertad sexual y reproductiva son los ejes de la política. Sin embargo, como parte de la vulneración de derechos en la calle, los derechos sexuales y reproductivos quizás han sido los menos pensados, tanto desde el sector salud, como dentro de los programas de atención a habitantes de calle. Sin embargo, se tendrá que actualizar el trabajo de campo para futuras investigaciones, intentando comprender cómo estos derechos están siendo garantizados y/o restituidos en el marco del IDIPRON u otras instituciones distritales como la Secretaría Distrital de la Mujer, frente a las lecturas de las mujeres como responsables de protegerse ante embarazos, y a la vez la imagen de los hijos que 
salvan a sus madres de la vida callejera. Así mismo, al interior de la institucionalidad se requiere de equipos especializados para atender situaciones de violencia sexual, principalmente en acceso a protocolos, donde se garantice a las mujeres acceso a estos servicios y se provean espacios y sesiones entre solo mujeres con funcionarias (Homeless Link, 2017).

Espero entonces contribuir desde las experiencias corporales, situadas en cuerpos que han sido violentados, a la consolidación de políticas efectivas que piensen la menstruación, la planificación y la gestación en situación de calle, y que además asuma como inaceptable la violencia sexual en estos contextos, desdibujando la imagen de mujer=casa, que justifica la victimización y refuerza estereotipos como la calle no es lugar para ellas/nosotras, lo cual tiene efectos no solo en quienes viven la calle, sino en quienes la transitamos diariamente en la ciudad, porque, finalmente, todas y todos nos movemos en el espacio calle y por los lugares que la configuran.

\section{Referencias}

ÁLVAREZ, Natalia Helena. "El género: una categoría necesaria para comprender la experiencia del desplazamiento forzado en Colombia". Revista Inclusión \& Desarrollo, Bogotá, v. 5, n. 1, p. 49-59, 2017.

ARFUCH, Leonor. El espacio biográfico. Dilemas de la subjetividad contemporánea. México: Fondo de Cultura Económica, 2010.

COLOMBIA. Ministerio de Salud. Política Nacional de Sexualidad, Derechos Sexuales y Derechos Reproductivos. Bogotá: Congreso de la República, 2010.

COLOMBIA. Alcaldía Mayor de Bogotá. Decreto 560 de 2015Política Pública Distrital para el Fenómeno de Habitabilidad en Calle, Bogotá: Consejo de Bogotá, 2015.

COLOMBIA. Departamento Administrativo Nacional de Estadística - DANE. Censo de Habitantes de Calle 2017. Bogotá: Secretaría Distrital de Integración Social, 2018.

DA SILVA ROSA, Anderson; PASARELLA, Anna Cristina. "Violence in the lives of homeless women in the city of São Paulo, Brazil". Interface COMUNICAÇÃO SAÚDE EDUCAÇÃO, v. 19, n. 53, p. 275-85, 2015. Disponible en 10.1590/1807-57622014.0221

DESPENTES, Virginie. Teoría King Kong. Bogotá: Penguin Random House, 2018.

UNITED KINGDOM. Homeless Link. Supporting women who are homeless. Briefing for homelessness services. Disponible en https://www.homeless.org.uk/sites/default/files/site-attachments/ Supporting\%20women\%20who\%20are\%20homeless\%20March\%202017_0.pdf. Fecha de acceso: 30/11/2018.

MAGLIANO, María José. "Interseccionalidad y migraciones: potencialidades y desafíos". Revista Estudos Feministas, Florianópolis, v. 23, n. 3, p. 691-712, septiembre-diciembre 2015.

MEDAN, Marina. "Articulaciones de edad y género en la construcción de feminidades en un programa de prevención del delito juvenil". Revista del Centro de Estudios Interdisciplinarios sobre Mujeres, Rosario, v. XXII, n. 23, p. 28-36, 2014.

PATEMAN, Carole. El contrato sexual. Barcelona: Anthropos, 1995.

PÉREZ-BUSTOS, Tania. "No es sólo una cuestión de lenguaje: lo inaudible de los estudios feministas latinoamericanos en el mundo académico anglosajón". ScientleStudia, São Paulo, v.15, n. 1, p. 5972, 2017.

RIBEIRO, Priscilla; PINTO, María Cristina; DA SILVA, Marcelo; MOURA DE OLIVEIRA, Deise; BARBOSA, Miriam. "Compreensão da vivência de mulheres em situação de rua". Revista da Escola de Enfermagem da USP, São Paulo, v. 50, n. 5, p. 750-756, 2016.

ROCHA DE SOUZA, Márcia Rebeca; FREITAS DE OLIVEIRA, Jeane; GUEDES CHAGAS, Mariana Cavalcante; SOUZA DE SANTANA CARVALHO, Evanilda. "Gender, violence and being homeless: the experience of women and high risk drug use". Revista Gaúcha Enfermagem, Porto Alegre. v. 37, n. 3, p. 1-9, 2016.

RODRÍGUEZ, Carolina. "Del cuerpo social al cuerpo femenino callejero: una mirada de las políticas sociales en Bogotá". Revista Papel Político. Bogotá, v. 20, n. 1, p. 101-125, enero-junio 2015. 
SEGATO, Rita Laura. La guerra contra las mujeres. Traficantes de sueños [online]. Madrid, España, 2016. Disponible en https://www.traficantes.net/sites/default/files/pdfs/map45_segato_web.pdf. Fecha de acceso: 30/11/2018.

TRUJILLO, Macarena. “Maternidad y prostitución ¿contradictorias y excluyentes?”. Revista Estudos Feministas, Florianópolis, v. 25, n. 1, p. 167-185, enero-abril 2017.

VIVEROS VIGOYA, Mara. "La interseccionalidad: una aproximación situada a la dominación”. Debate Feminista, Ciudad de México, n. 52, p. 1-17, 2017.

ZICAV, Eugenia; ASTORINO, Julieta; SAPOROS, Lucas. "Leyes que son cuerpo / cuerpos que son leyes: proyectos de ley de aborto en Argentina”. Revista Estudos Feministas, Florianópolis, v. 25, n. 3, p. 1183-1197, septiembre - diciembre 2017.

Carolina Rodríguez Lizarralde (crodriguezl@unal.edu.co) es estudiante del Doctorado en Ciencias Humanas y Sociales, Magistra en Política Social y Politóloga. Docente de la Fundación Universitaria Monserrate, con 8 años de experiencia en análisis de políticas sociales dirigidas a la población habitante de calle en Bogotá, desde un enfoque de género y centrada en niñas, niños y jóvenes en la ciudad de Bogotá. En su tesis doctoral está pensando las experiencias callejeras en términos de interseccionalidad.

\section{COMO CITAR ESTE ARTÍCULO, DE ACUERDO CON LAS NORMAS DE LA REVISTA:}

LIZARRALDE, Carolina Rodríguez. "Vivir en la calle: experiencias corporales para pensar los géneros en Bogotá (Colombia)". Revista Estudios Feministas, Florianópolis, v. 28, n. 2, e 60498, 2020.

\section{CONTRIBUCIÓN DE AUTORÍA}

No se aplica.

\section{FINANCIACIÓN}

No se aplica.

\section{CONSENTIMIENTO DE USO DE IMAGEN}

No se aplica.

\section{APROBACIÓN DE COMITÉ DE ÉTICA EN INVESTIGACIÓN}

No se aplica.

\section{CONFLICTO DE INTERESES}

No se aplica.

\section{LICENCIA DE USO}

Este artículo está licenciado bajo la Licencia Creative Commons CC-BY Internacional. Con esta licencia se puede compartir, adaptar, crear material para cualquier objetivo, siempre que se le atribuya la autoría.

\section{HISTORIAL}

Recibido el 30/11/2018

Presentado nuevamente el 17/08/2019

Aprobado el 04/11/2019 